\title{
Use of lactation models to develop a cow performance monitoring tool in smallholder dairy farms
}

\author{
Bettie S. Kawonga', Mizeck G. G. Chagunda², Timothy N. Gondwe', Serah R. Gondwe³ \\ and James W. Banda ${ }^{1+}$
}

${ }^{1}$ Animal Science Department, Bunda College of Agriculture, Lilongwe University of Agriculture and Natural Resources, Lilongwe, Malawi, ${ }^{2}$ Future Farming Systems Group, SRUC Research, Edinburgh, UK, ${ }^{3}$ Agribusiness Management Department, Bunda College of Agriculture, Lilongwe University of Agriculture and Natural Resources, Lilongwe, Malawi

\begin{abstract}
Animal performance monitoring is of enormous value for management decision-making at the individual farmer level as well as for the industry and country as a whole. The aim of the study was to develop a performance monitoring tool for existing smallholder dairy production system based on lactation curves. For this purpose three equations of Wood (1967), critical exponential and double exponential were compared to evaluate their fitting and prediction ability. The full data set comprised of 11481 daily milk records for HolsteinFriesian in various stages of lactation. Data of 84 Holstein-Friesian cows was used to develop lactation curves. Within each lactation, only milk yield from calving until 330 days post-calving were used. The three models were evaluated using three criteria which were the amount of variation accounted for by the model (coefficient of determination), b-value and distribution of residuals. Based on these criteria, the double exponential equation was selected for developing the cow performance monitoring (CPM) curve. The CPM curve was developed based on the mean lactation curve with its confidence interval generating the upper and lower limits. The CPM curve had high prediction rates (sensitivity=93\% and specificity=93\%) hence efficient enough to guide routine management of dairy animals in smallholder farms.
\end{abstract}

Keywords: cow performance monitoring, smallholder dairy, lactation models

\section{Introduction}

The smallholder dairy sector is the largest subsector in Malawi dairy industry, accounting for about 49193 metric tones of milk produced in 2008 which is approximately $80 \%$ of the total milk production (DAHLD 2008). Due to the increased stakeholder participation and government priorisation of dairy within the livestock sector through its five year heifer program, dairy production has experienced growth of about $10 \%$ a year for the past decade (Malawi Government 2008). This growth has been attributed to government and non-governmental organisations (NGOs) such as Land O' Lakes with funding from USAID, Small-scale Livestock Promotion Program, World Vision Malawi and ARDEP who incorporated dairy development in their rural programs. This has resulted in increased number of improved dairy animals. In

$\dagger$ As this manuscript was going through the review process, the project team lost a trusted teacher, colleague and mentor. Professor James W. Banda departed from our midst. May his soul rest in peace. 
2008 there were 30272 dairy animals in Malawi, a number that represents an annual increase of roughly $30 \%$ over the previous five year period (DAHLD 2008). The growth of the dairy sector has contributed to increased household incomes for dairy farmers. Lilongwe milk shed area is the second most important milk producing area in Malawi, with over $19 \%$ of total milk supplied to processors, and it has experienced high growth than other milk shed areas. Despite government and NGOs efforts to increase dairy production in Malawi, inadequate feeding and management practices have made it difficult for dairy farmers to increase productivity. For increased productivity, herd recording and monitoring are not only a prerequisite to increased dairy productivity but provides a basis for genetic, economic and production evaluations. Over a decade ago, Chagunda et al. (1998) reported that in Malawi holistic dairy development evaluations for herd monitoring and assessment based on large amounts of longitudinal data were difficult if not impossible to carry out because of the unavailability of systematic records. The situation has not changed to date. Lack of animal recording is a barrier to developing tools to monitor management problems in dairy, and develop a genetic evaluation system for long term local breeding of dairy breeds. This makes it difficult for the current efforts to achieve long term gains that would improve productivity and generate the much needed appropriate breeding stock. Lack of performance records leaves the dairy farmers with no proper basis for decision making and bench marking.

Recording of animal performance is of enormous value for management decisions for both individual farmer and for the industry or country as a whole. It has been well established that integration of performance recording in farming system contribute to increased productivity as milk records can be used as a diagnostic tool for detecting different kinds of health and reproduction issues in the herd (Falvey \& Chantanthalaka 1999). In modern dairy farming, successful management relies on good record keeping and on knowledge that can be derived from it. Further to the primary purpose of measuring production of individual cows dairy recording systems support overall breed improvement (Falvey \& Chantanthalaka 1999). In this connection, the hypothesis is that for livestock record systems, graphical reports may be more powerful than numerical reports. Performance graphs allow the dairy farmer to visualise the possible impact of diseases and feeding on milk yield, milk composition, body weight, and some others health-related indices. An unexpected milk yield decrease in an individual cow may serve as a warning of pending or current sickness. The timely elimination of these failures can lead to the prevention of diseases (Moallem et al. 2002).

The objective of the study was to develop a cow performance monitoring tool for existing smallholder dairy production system and hence demonstrate the practical application of animal recording. One significant advantage of performance monitoring graph is in detecting individual or groups of animals that are not performing as expected, or fall outside of normal limits. Graphs that summarise the performances of groups of cows provide an opportunity to define management trends and weaknesses, to check the welfare of animals and to isolate cows that fall outside of normal limit. This would give farmers/extension workers immediate information on the health, nutrition (feeding) and general physiological status of individual cows on day to day basis. The process is hoped to link farmers, researchers and extension workers to correctly and timely analyse data from recording scheme, interpret the results and provide feedback to farmers for management interventions. 


\section{Materials and methods}

\section{Study area and animals}

Lilongwe milk shed area is in the central region of Malawi and falls under Central Region Milk Producers Association (CREMPA). There are a total of 18 milk bulking groups in this milk shed area under Lilongwe Agriculture Development Division (LADD). There are about 1500 smallholder dairy farmers.

Data for the current study were collected from studies on-farm in four milk bulking groups of Machite, Chitsanzo, Dzaonewekha and Lumbadzi in Lilongwe and Dedza districts of Lilongwe milk shed area. During the study, the area received an average of $850 \mathrm{~mm}$ of rainfall between November 2009 and April 2010. The study was conducted during rainy season. Cows were stall-fed (cut-and-carry) and had access to some concentrates (maize bran, dairy mash) during morning and evening milking. The cows were milked twice a day, in the morning and late in the afternoon.

The study focused on monitoring individual dairy farms with at least one lactating cow. The selected farmers were given developed recording sheets for recording daily milk yields, heat dates, service dates and method of service, signs of sickness and dates and treatments. Data collected included information such as animal identification number or name, its pedigree, parity, days in milk, calving history, service dates, expected date of calving and drying-off date.

Data were obtained for 84 Holstein-Friesian cows. The full data set comprised of 11481 daily milk records for cows in various stages of lactation. The data was edited for errors in recording (i.e. missing records for one month and over-estimation of daily milk yield). Within each lactation, only milk yield from calving until 330 days post-calving were used as it has been shown that the concurrent pregnancy in lactating dairy cows causes a depression in milk yield in the last 18 weeks of pregnancy (Hooper 1923, Coulon et al. 1995).

\section{The models}

Three different models were tested. The model would form a basis for the cow performance monitoring (CPM) curve. The three equations used were Wood's equation (Wood 1967), critical exponential equation and double exponential equation. Detailed descriptions for the three equations are: Wood's equation

$$
y_{t}=a t^{b} \cdot \exp (-c t)
$$

where $y$ is the milk yield per day, $t$ is days from calving, $a, b$ and $c$ are the parameters of the Wood's equation. Parameter $a$, approximates the initial yield, $b$ is the inclining slope parameter and $c$ is the declining slope parameter.

Critical exponential equation,

$$
y_{t}=a+((b+c t) \cdot \exp (r t))
$$

where $y$ is the milk yield per day, $t$ is days post calving, $a, b, c$ and $r$ are the parameters of the critical exponential equation. Parameter $a$ approximates the initial yield, parameter $b$ is the inclining slope parameter, $c$ is the declining slope parameter and $r(<1)$ is the constants. Double exponential equation,

$$
y_{t}=a+(b \cdot \exp (r t))+c \cdot \exp (s t)
$$


where $y$ is the milk yield per day, $t$ is days post calving, $a, b, c, r$ and $s$ are the parameters of the critical exponential equation. Parameter $a$ approximates the initial yield, $b$ the is inclining slope parameter, $c$ is the declining slope parameter and parameters $r$ and $s($ all $<1$ ) are constants.

The main interest was to find an equation that provided a good description of the lactation curve for cows within a range of lactation length. The results were used in developing a CPM curve to determine optimal performance. The numbers of daily records were highly variable because some farmers dried off their cows earlier than at seven months of pregnancy due to low milk yields.

\section{Developing the cow performance monitoring curve}

The non-linear regression was used to plot lactation curves of daily milk yield ( $\mathrm{y}$ ) relative to days in milk (t) for Wood's equation, critical exponential equation and double exponential equation. This was done using Genstat Discovery Edition 3 (VSN International Ltd, Hemel Hempstead, UK). Goodness of fit of equations was evaluated according to the following criteria; estimate of b value, residual mean and coefficient of determination $\left(R^{2}\right)$. Equation with best overall performance according to mentioned criteria was selected.

Data was fitted separately for individual cows and the effect of parity on curve parameters was evaluated. Cows were grouped either as first parity cows or multiparous cows. Statistical evaluation was done using three criteria i.e. comparison of mean residuals, comparison of coefficient of determination (1-ratio of the residual sum of squares to the total sum of squares) and comparison of the b value.

\section{Validating of the CPM curve}

The health status of the cows and exhibition of signs of oestrus were used to test the sensitivity and specificity of the CPM curve. The study used data from each animal retrospectively. The performance of the CPM curve was checked against the cow's condition at the time of data collection. The animals were categorised either as healthy or problematic cows (sick cows and on heat). Three versions of the CPM curve based on the mean and deviations from the mean ( $90 \%$ and $95 \%$ confidence intervals) were derived. The three versions were CPM curve1 (based on the mean), CPM curve 2 (based on $90 \%$ confidence interval) and curve 3 (based on $95 \%$ confidence interval) tested using sensitivity and specificity as applied by Chagunda et al. (2006). The two groups of cows, one with known problems and the other, a healthy group of cows, were used in the test. Fifteen cows ( 13 classified as sick cows and 2 cows on heat) and another 15 healthy cows were used. Cases where the CPM curve predicted a problematic cow that coincided with a defined problem (defined from farmer records and veterinary treatment) were characterised as true positives (TP) and cases where the CPM curve failed to predict a defined problem were considered false negatives (FN). True negatives (TN) represented occasions where no problem was predicted and the cows were healthy. Cases where healthy cows were classified as problematic cows based on CPM curve were defined as false positives (FP). Sensitivity was the probability of predicting cows that were defined as problematic cows as problem cows and specificity was the probability of predicting cows defined as healthy as healthy cows. Sensitivity was calculated as a percentage of problematic cows:

$$
\text { Sensitivity }=\frac{T P}{T P+F N} \times 100
$$


Specificity was calculated as a percentage of cows that were correctly classified as healthy:

$$
\text { Specificity }=\frac{T N}{F P+T N} \times 100
$$

\section{Results}

The fitted curves and the observed data are presented in Figures 1 and 3 . The results show a better fit by the double exponential model than the critical exponential equation and the Wood's equation. The Wood's equation showed difficulties fitting the initial yield. The critical exponential equation showed difficulties fitting the peak yield.
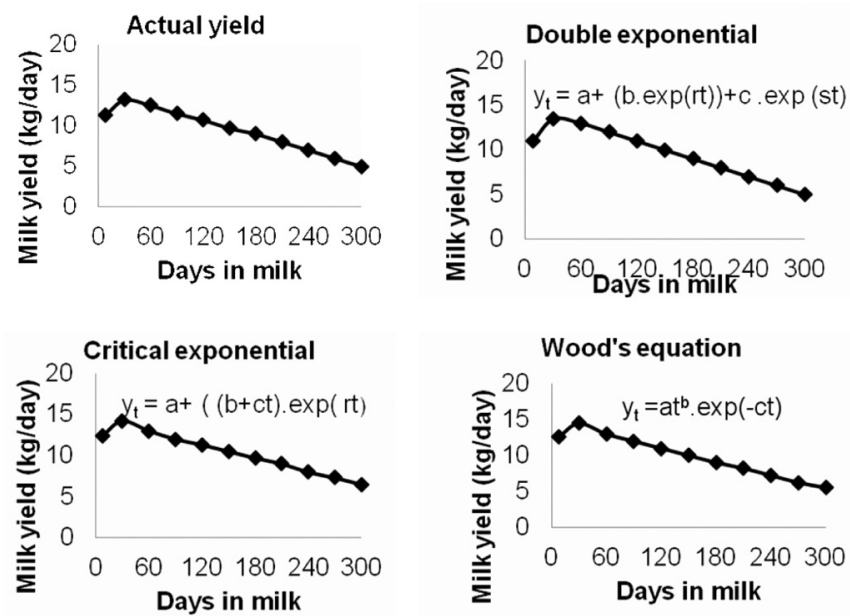

\section{Figure 1}

Wood's equation, critical exponential equation and double exponential equation fitted to average lactation data for first parity HolsteinFriesian cows.

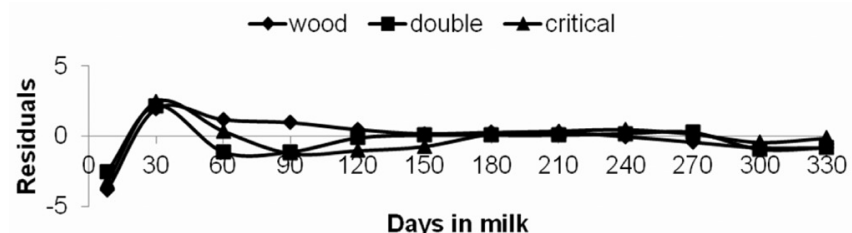

Figure 2

Residual plots for the Wood's equation, double exponential equation and the critical exponential equation for first parity Holstein-Friesian cows.

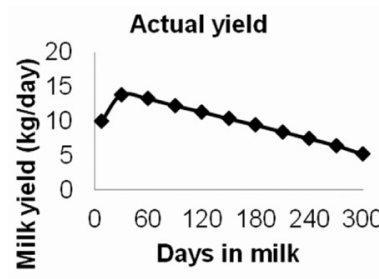

\section{Double exponential}
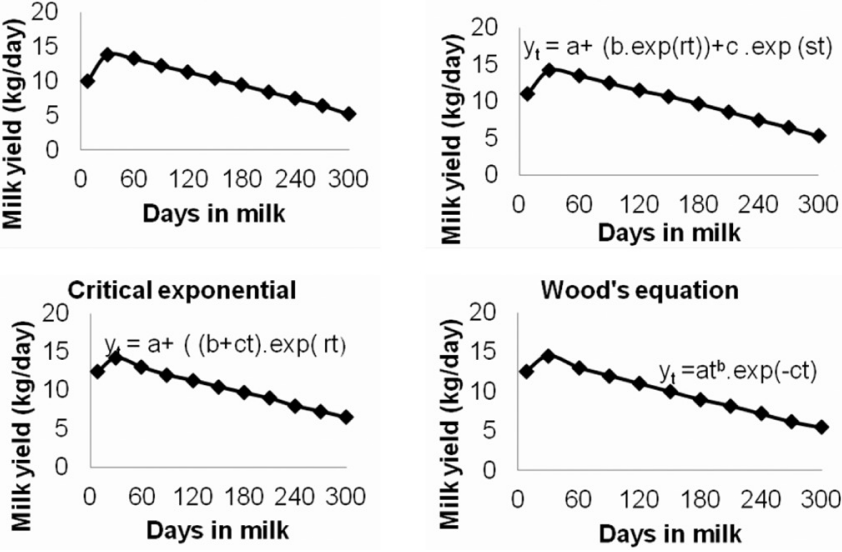

Wood's equation

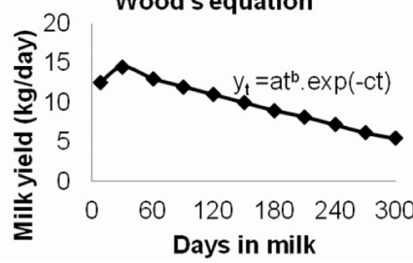

Figure 3

Wood's equation, critical exponential equation and double exponential equation fitted to lactation data for multiparous HolsteinFriesian cows 
Plot of residuals to identify difficulties in prediction by a particular model are presented in Figures 2 and 4 . The results show a tendency for greater deviations from zero in the residuals around early lactation by all three equations. This indicated systematic mis-prediction in early lactation by all the three equations. In late lactation, the double exponential equation and the critical exponential equation had greater deviations from zero whereas the Wood's equation provided a closer fit.

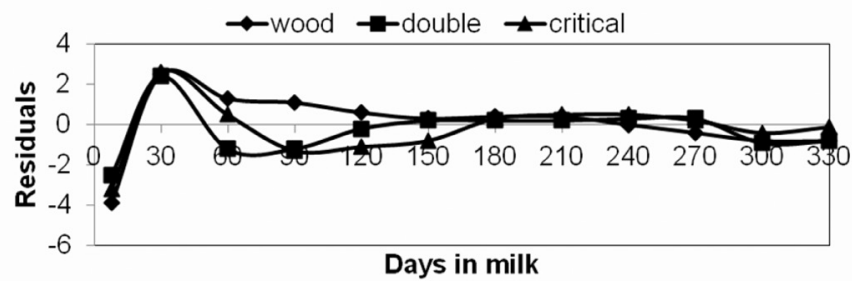

Figure 4:

Residual plots for the Wood's equation, double exponential equation and the critical exponential equation for multiparous Holstein-Friesian cows

Results of the statistical performance of Wood's equation, double exponential equation and critical exponential equation when applied to lactation curves of 84 cows are presented in Table 1. Average residual value (average value of the difference between predicted and observed values) was relatively smaller for Wood's equation $(-0.02)$ than for the critical exponential equation (-0.05) and double exponential equation (0.03). However, the average residual values of the three models were not significantly different. This indicated that on the basis of average residual values, all the three equations fitted the lactation data used in the current study, in a similar way.

Table 1

Residual means for comparing goodness of fit of Wood's equation, double exponential equation and critical exponential equation

\begin{tabular}{lccc}
\hline Variable & Residual mean & SED & $P$ \\
\hline Wood's equation vs & -0.02 & 0.33 & 0.87 \\
Double exponential & 0.03 & & 0.91 \\
Wood's equation vs & -0.02 & 0.21 & 0.77 \\
Critical exponential & -0.05 & 0.26 & \\
Double exponential vs & -0.05 & & \\
Critical exponential & 0.03 & &
\end{tabular}

SED: standard error of the difference, Residual mean: the mean difference between predicted and observed values

Table 2

Coefficient of determination $\left(R^{2}\right)$ and curve parameters for Wood's equation, double exponential equation and critical exponential equation

\begin{tabular}{lllllll}
\hline Variable & $\mathrm{R}^{2}$ & $\mathrm{a}$ & $\mathrm{b}$ & $\mathrm{c}$ & $\mathrm{r}$ & $\mathrm{s}$ \\
\hline Wood's equation & 95.9 & 0 & 20.1 & -5.8 & & \\
Critical equation & 98.3 & 1.6 & 10.1 & 0.2 & 0.9 & \\
Double exponential equation & 99.5 & 1 & 18.4 & -7.9 & 0.9 & 0.9 \\
\hline
\end{tabular}

a: initial yield, b: inclining slope, c: declining slope, r, s: constant in Wood's equation, double exponential equation and the critical exponential equation, $R^{2}$ : the measure of the precision (how much of the variation is being accounted for by the fitted model) 
Statistics of goodness-of fit ( $R^{2}$ and $b$-value) are presented in Table 2. Coefficient of determination $\left(R^{2}\right)$ was higher for double exponential equation $\left(R^{2}=0.99 \%\right)$ than for Wood's equation $\left(R^{2}=0.96\right)$ and critical exponential equation $\left(R^{2}=0.98\right)$. This indicated that the double exponential equation provided a better fit than Wood's equation and critical exponential equation. Parameter $b$ which is an inclining slope parameter was compared among the Wood's equation, double exponential equation and critical exponential equation. The double exponential estimated a more practical b value (18.4) than the Wood's equation and the critical exponential equation when compared to the lactation data used in the current study. The Woods equation over predicted the $b$-value (20.1) where as the critical exponential equation under predicted the $b$ value (10.1). These results ( $R^{2}$ and $b$ value) indicate that the double exponential equation exhibited better qualities to fit the lactation data used in the present study than the Wood's equation and the critical exponential equation.

Based on the above described test, the double exponential equation was selected for developing the CPM curve.

\section{Validating the CPM curve}

For the purpose of testing the CPM curve, only milk yield data from calving up to 330 days in milk were used. Plots of milk yield ( $\mathrm{kg} / \mathrm{day}$ ) relative to days in milk for mean of the exponential equation curve (curve 1) the CPM curve with $95 \% \mathrm{Cl}$ (curve 2) and CPM curve with $90 \% \mathrm{Cl}$ (curve 3) and are presented in Figures 5 to 7 . Figure 6 shows that the CPM curve 2
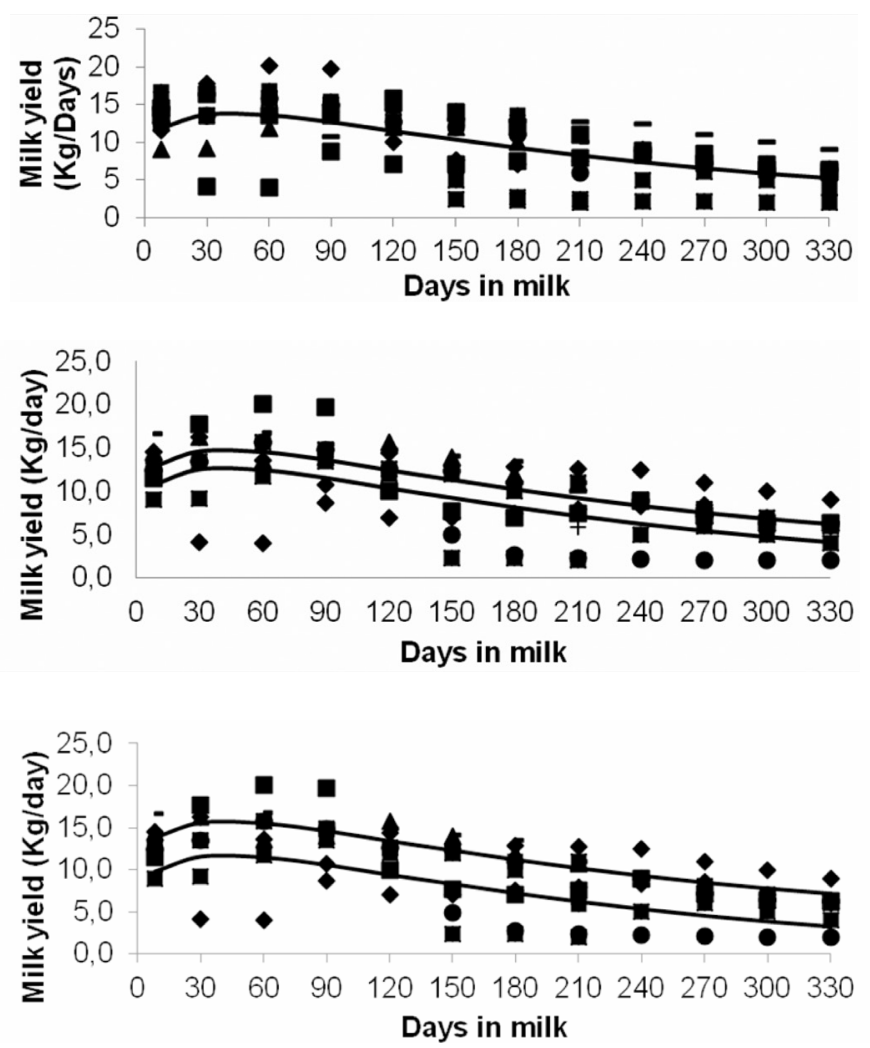

Figure 5

Plot of curve 1 (exponential equation) and lactation curves for 10 cows

Figure 6

Plot of CPM curve 2 and lactation curves for 10 cows

Figure 7

Plot of CPM curve 3 and lactation curves for 10 cows 
identified six cows as below the lower limit of performance. Figure 7 shows that the CPM curve 3 identified four cows as being below lower limit of performance. Figure 5 shows that curve 1 (exponential curve) identified seven cows as being below lower limit of performance. The results show that CPM curve 2 was closer to the curve 1 in identifying cows that were below lower limit of performance than CPM curve 3. Based on this test the CPM curve 2 was selected for testing its prediction ability (sensitivity and specificity).

The sensitivity and specificity for the CPM curves are presented in Table 3 . The sensitivity of the three curves for detecting problem cows and cows on heat ranged from $69-93 \%$. The specificity for correctly classifying health cows ranged from $92-93 \%$ for the three curves. Curve 1 and curve 2 had the highest sensitivity value (93\%) compared to curve $3(87 \%)$. An increase in sample size to 15 cows increased the sensitivity of CPM curve 2 by (2\%), CPM curve 3 by $3 \%$ and curve 1 by $2 \%$. The corresponding increase in the specificity was $1 \%$ for all the curves.

Table 3

Sensitivity and specificity to distinguish between health and problematic cows at different sample sizes using CPM curves

\begin{tabular}{lccccccc}
\hline Stage of Lactation & Cow & \multicolumn{2}{c}{ CPM curve 1 } & \multicolumn{2}{c}{ CPM curve 2 } & \multicolumn{2}{c}{ CPM curve 3 } \\
& status & sens, \% & spec, \% & sens, $\%$ & spec, \% & sens, \% & spec, \% \\
\hline Early lactation & $\mathrm{H}^{*}$ & 92 & 92 & 85 & 92 & 92 & 92 \\
Mid lactation & $\mathrm{O}^{* *}$ & 93 & 93 & 87 & 93 & 93 & 93 \\
& $\mathrm{H}^{*}$ & 77 & 92 & 69 & 92 & 85 & 92 \\
Late lactation & $\mathrm{O}^{* *}$ & 80 & 93 & 73 & 93 & 87 & 93 \\
& $\mathrm{H}^{*}$ & 85 & 92 & 77 & 92 & 85 & 92 \\
\hline
\end{tabular}

*Only cows with health problems included, $\mathrm{n}=10,{ }^{* *}$ Includes cows that had health problems and those that were seen on heat, $\mathrm{n}=15$, sens: sensitivity, spec: specificity

\section{Discussion}

The results of curve fitting indicated that the double exponential equation was robust and closely resembled the actual lactation curves. The wood's equation predicted the actual lactation fairly well, but with slight difficulties in prediction of early lactation. This observation is in line with earlier reports (Sherchards et al. 1995, Dijkstra et al. 2009), who reported that although the Wood's equation can give an acceptable fit to milk yield data from a given lactation, it tends to over-predict during early and late lactation and under-predict data during mid-lactation. The critical exponential equation had difficulties similar to Wood's equation in fitting lactation curve around early lactation. Residuals of the three equations showed a tendency for greater deviation from zero in early lactation and end of lactation. This agrees with earlier reports (Gipson \& Grossman 1989, Vargas et al. 2000), who reported that many existing models show systematic deviation from actual milk yield, especially at the beginning and end of lactation. This indicated sensitivity of the three equations to the prediction process and the data used. One possible explanation for the poor performance of the three equations during early lactation and late lactation is the naturally high variation in milk yield between animals that occurs in early and late lactation. This agrees with Dijkstra et al. (2009) and Tozer \& Taylor (1999), who reported that where the number of pre-peak observations is 
small, equations tend to result in larger residual values. However as lactation progressed, all equations tend to predict similarly with very small residual values. The differences in early lactation are a result of the functional form of each equation, and as lactation progresses, the lactation curve becomes nearly linear and the equations can more readily predict this linearity rather than the non-linear shape of the early lactation. The Wood's equation was able to predict late lactation more closely with smaller residual value than double exponential equation and critical exponential equation. As observed with early lactation data, the late lactation data could have been more variable which contributed to difficulties in prediction by the equations. In line with earlier reports, Dijkstra et al. (2009), Wood's equation shows greater ability to find a closer fit resulting in smaller residual values. These results show the importance of using the right amount and distribution of data to obtain a satisfactory fit of the Wood's equation, double exponential equation and the critical exponential equation. Thus the less satisfactory fit of the Wood's equation, double exponential equation and the critical exponential equation to data especially in early lactation, can be explained by inadequacy of data.

Residual mean values of Wood's equation, critical exponential equation and double exponential equation showed no significant difference among the three equations. This indicates that the residual mean was not able to discriminate between the goodness of fit of different equations, so despite the results of model fit, the three equations were of the same rank in fitting of the average lactation data. Coefficient of determination $\left(R^{2}\right)$ was high in general and ranged from 0.96 and 0.99 . This high level of accuracy for both Wood's and exponential equations has also been reported in other studies (e.g. Mukundan \& Bhat 1983, Vargas et al. 2000, Dijkstra et al. 2009). The performance of the individual equations varied with the double exponential predicting $b$ value more accurately than the Wood's equation and the critical equation. However, all equations showed systematic deviation from the actual milk yield in accordance with Vergas et al. (2000). The Wood's equation over predicted milk production during early lactation and had a higher $b$ value than practically possible. This result is in contrast to that of Fathi Nasri et al. (2008), who found that the Wood's equation under-predicted milk production in early lactation. One possible reason for the difference is the type of management between farms. In the study of Fathi Nasri et al. (2008), data used for testing models was obtained from cows under one management system fed in a way that reflected potential production. In the current study, data was obtained from cows from different smallholder farms and hence management could be different between farms. This is despite the fact that the cows were under the same broad management systems, smallholder dairying. However the results are in agreement with Rook et al. (1993) and Dijkstra et al. (2009), who reported that Wood's equation tended to over-predict milk production in early lactation. The step-wise procedure which used a combination of model fit and statistical evaluation to test the goodness of fit of the three models was found to be appropriate to achieve a reliable solution for the data set used in the current study. The use of $R^{2}$ and the $b$ value assisted in evaluating similarities and differences among the three equations. As pointed by Motulsky \& Ransnas (1987), statistical measures are important in dealing with the question of which model to use.

Testing of suitability of CPM curves (curve 1, curve 2 and curve 3 ) to be used as a monitoring tool for smallholder dairy system showed that CPM curve 2 was a better model 
than CPM curve 3, with more stable sensitivity value for classifying cows based on their condition (health and heat). A change in sample size showed that sensitivity values for CPM curve 2 were more stable than CPM curve 3. This indicated that CPM curve 2 is a more stable tool for monitoring cow performance than CPM curve 3. Stable and high sensitivity and specificity values are the desired characteristics of a good monitoring tool. This is because misclassifying cows' condition may have considerable practical and economic implications for both the dairy farmer and extension worker. Rasmussen et al. (2005), reported that correct classification of cow's health status puts heavy demands on the detection system. The ability of the CPM model to correctly classify condition of cows increased with increase in sample size. This indicated a reduction in the sample error. This is because increase in sample size, reduces variation in the sample hence smaller sampling error and high precision.

In conclusion, three empirical equations were compared based on criteria to measure goodness of fit. The results of this study showed that the double exponential equation was an accurate equation to describe the average lactation curve for Malawi smallholder dairy cows. CPM curve, which was based on $95 \%$ coefficient interval, had the ability to classify cows according to their condition (normal vs. problem cows) hence suitable to be used as a monitoring tool for smallholder dairy production system. The ability of the cow performance monitoring curve to correctly classify cows according to their condition improved with increase in sample size. The results showed that improvement on the ability of the CPM curve was possible with large sample size. The CPM curve needs to be tested using large sample size for further improvement on its prediction rates.

\section{Acknowledgements}

This study was conducted as part of the Optimising Smallholder Dairying project portfolio. Optimising Smallholder Dairying project was a Scottish Government International Development Fund funded project based at the SAC Dairy Research Centre, Dumfries, Scotland. The authors thank the Scottish Government for the financial assistance. The authors also greatly appreciate the fruitful discussions and contribution from Dr David Roberts, Head of SAC Dairy Research Centre and the constructive criticism from the anonymous reviewers. Many thanks also go to the smallholder dairy farmers of Lilongwe milkshed area in Malawi.

\section{References}

Chagunda MGG, Wollny CBA, Bruns E, Kamwanja LA (1998) Evaluation of the artificial insemination programme for small-scale dairy farms in Malawi. Arch Tierz 41, 45-51

Chagunda MGG, Larsen T, Bjerring M, Ingvartsen KL (2006) L-lactate dehydrogenase and N-acetyl- $\beta$-Dglucosaminidase activities in bovine milk as indicator of non-specific mastitis. J Dairy Res 73, 431-440

Coulon JB, Pérochon L, Lescourret F (1995) Modelling the effect of the stage of pregnancy on dairy cows' milk yield. Anim Sci 60, 401-408

DAHLD=Department of Animal Health and Livestock Development (2008) Annual Livestock Census. Ministry of Agriculture and Food security, Lilongwe, Malawi

Dijkstra J, Lopez S, Bannink A, Dhanoa MS, Kebreab E, Odongo NE, Fathi Nasri MH, Behera UK, HernandezFerrer D, France J (2009) Evaluation of a mechanistic lactation model using cow, goat and sheep data. J Agric Sci 148, 249-262 
Falvey L, Chantanthalaka C (1999) Smallholder dairying in the tropics. International Livestock Research Institute, Nairobi, Kenya

Fathi Nasri MH, France J, Odongo NE, Lopez S, Bannink A, Kebreab E (2008) Modelling the lactation curve of dairy cows using differentials of growth functions. J Agric Sci 146, 633-641

Genstat Discovery Edition 3 (2003) Genstat Release 7.2.2, VSN International Ltd.

Gipson TA, Grossman M (1989) Diphasic analysis of lactation curves in dairy goats. J Dairy Sci 72, 1035-1044

Hooper JJ (1923) Studies of dairy cattle. II. Milk production. Ky Agric Exp Stn Bull 248, 65-85

Malawi Government (2008) Annual economic report. Ministry of Economic Planning and Development, Lilongwe, Malawi

Moallem U, Gur R, Shpigel N, Maltz E, Livshin N, Yacoby S, Antman A, Aizinbud E (2002) Graphic monitoring of the course of some clinical conditions in dairy cows using a computerized dairy management system. Israel J Vet Med 57, P2, 43-64

Motulsky HJ, Ransnas LA (1987) Fitting curves to data using nonlinear regression: a practical and nonmathematical review. FASEB Journal 1, 365-374

Mukundan G, Bhat PN (1983) Lactation curves in Malabari Goats and their Saanen Half-Breds. Milk Production. Ind J Anim Sci 53, 666-669

Rasmussen MD, Bjerring M, Skjøth F (2005) Visual appearance and CMT score of foremilk of individual quarters in relation to cell count of cows milked automatically. J Dairy Res 72, 49-56

Rook AJ, France J, Dhanoa MS (1993) On the mathematical description of lactation curves. J Agric Sci 121, 97102

Sherchand L, Mcnew RW, Kellogg DW, Johnson ZB (1995) Selection of a mathematical model to generate lactation curves using dairy milk yields of Holstein cows. J Dairy Sci 78, 2507-2513

Tozer PR, Taylor CC (1999) Mathematical equations to describe lactation curves for Holstein-Friesian cows in New South Wales. Aust J Agric Res 50, 431-440

Vargas B, Koops WJ, Herrero M, Van Arendonk JAM (2000) Modeling extended lactations of dairy cows. J Dairy Sci 83, 1371-1380

Wood PDP (1967) Algebraic model of lactation curve in cattle. Nature 216, 164-165

Received 20 May 2011, accepted 23 April 2012.

Corresponding author:

Mizeck G. G. Chagunda

email: mizeck.chagunda@sruc.ac.uk

SRUC Research, Kings Buildings, West Mains Road, Edinburgh, EH9 33G, Scottland, UK 